\title{
A IMPORTÂNCIA DA LINHA DE CUIDADOS PALIATIVOS E O PAPEL DA ASSISTÊNCIA DOMICILIAR (AD) COMO GESTORA DESSE PROCESSO
}

Eixo temático: Avaliação e Qualidade do Cuidado

Ana Paula Mansano; Paula Rossi;

Introdução: A rede de atenção à saúde (RAS) é composta pelos serviços e equipamentos de saúde que tem o objetivo de assistência integral, perpassando por três modalidades: a preventiva, a terapêutica e a paliativa. A atenção paliativa é focada nas necessidades do cuidado com o paciente desde o diagnóstico de uma doença não curável $\left.\right|^{(1,2)}$, investindo-se na melhora da qualidade de vida e na sua capacidade de lidar com a situação de maneira adaptativa. Ao identificarmos casos de pacientes com doenças sem possibilidade de intervenção curativa, iniciamos a interlocução com o paciente e seus atores coadjuvantes: familiares, equipamentos de saúde, trabalhando o link entre o desejo do paciente e as possibilidades de qualificar seu tempo de vida. Nessa tratativa, enxergamos a $A D$ como fonte de articulação intersetorial dentro de uma linha de cuidado ainda não desenhada. A partir de casos acompanhados em nosso Serviço, construímos essa linha de cuidado, desde o convencimento e sensibilização do serviço especializado até a entrevista com os familiares para propor a doação de tecidos (córneas).

Objetivo: mostrar a importância da AD como componente da RAS na estruturação e gerenciamento da assistência em cuidados paliativos $(\mathrm{CP})$.
Relato de Experiência: A família do Sr. L.F., 79 anos, procura a Unidade Básica de Saúde (UBS) para investigar o motivo de perda de peso progressiva, no acolhimento foi agendada uma consulta com médico clínico e realizada uma solicitação de atendimento domiciliar Programa Melhor em Casa - (PMC). Após consulta com médico, o paciente foi referenciado para o gastrooncologista (rede terciária) com urgência, com diagnóstico de neoplasia de estômago (metástase pulmonar? Hepática? Intestino?) e após visita da equipe multiprofissional da $A D$ do PMC o Sr. L.F. também foi admitido para seguimento. $O$ paciente realizou avaliação com gastro-oncologista no prazo estipulado pela lei e iniciou tratamento com quimioterapia neoadjuvante. $O$ acompanhamento multiprofissional foi realizado pela equipe do PMC devido às condições clínicas e recomendações para CP. Após 2 meses de acompanhamento o paciente evoluiu à óbito no domicílio, cumprindo seu desejo em ajudar o próximo, foi realizada a entrevista com os familiares para propor a doação de córnea, após o aceite dos seus filhos foi contato a Organização de Procura de Órgãos e Tecidos (OPO) e foi efetivada a doação das córneas com retirada no próprio domicílio.

\section{LINHA DE CUIDADO: Fluxos Assistenciais Seguros}

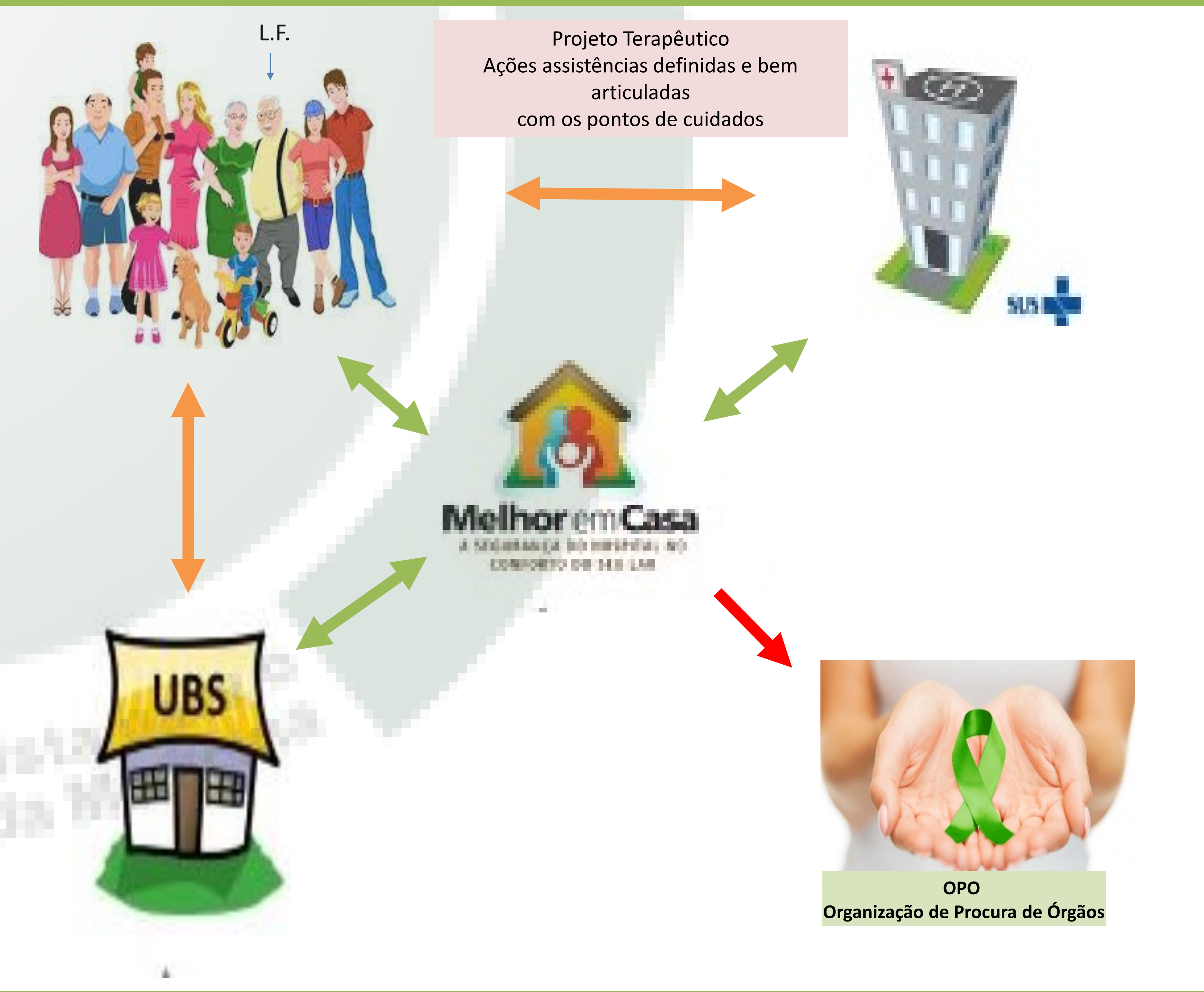

Resultado: Observou-se que houve um engajamento da equipe de assistência domiciliar, junto aos diferentes níveis assistenciais, quais sejam primário, secundário e terciário, fortalecendo desde a recomendação por CP até, como consequência, a sensibilização familiar e a doação de tecidos.

\section{Conclusão}

Concluímos através do relato de experiência que há necessidade de estruturar a linha de cuidados paliativos, entendendo que a AD poderá assumir um papel estratégico na articulação com os demais níveis de assistência, sendo gestora dessa linha de cuidado. 